Food preference and performance of the larvae of a specialist herbivore: variation among and within host-plant populations

Leimu, Roosa; Riipi, Marianna; Stærk, Dan

Published in:

Acta Oecologica

DOI:

10.1016/j.actao.2005.06.004

Publication date:

2005

Document version

Publisher's PDF, also known as Version of record

Citation for published version (APA):

Leimu, R., Riipi, M., \& Stærk, D. (2005). Food preference and performance of the larvae of a specialist herbivore: variation among and within host-plant populations. Acta Oecologica, 28, 325-330.

https://doi.org/10.1016/j.actao.2005.06.004 
Original article

\title{
Food preference and performance of the larvae of a specialist herbivore: variation among and within host-plant populations
}

\author{
Roosa Leimu ${ }^{\mathrm{a}, *}$, Marianna Riipi ${ }^{\text {a }}$, Dan Stærk ${ }^{\mathrm{b}}$ \\ a Section of Ecology, Department of Biology, University of Turku, 20014 Turku, Finland \\ ${ }^{\mathrm{b}}$ Department of Medicinal Chemistry, The Danish University of Pharmaceutical Sciences, Universitetsparken 2, 2100 Copenhagen, Denmark
}

Received 27 August 2004; accepted 7 June 2005

Available online 14 July 2005

\begin{abstract}
Specialist herbivores are suggested to be unaffected by or attracted to the defense compounds of their host-plants, and can even prefer higher levels of certain chemicals. Abrostola asclepiadis is a specialist herbivore whose larvae feed on the leaves of Vincetoxicum hirundinaria, which contains toxic alkaloids and is unpalatable to most generalist herbivores. The food choice, leaf consumption and growth of $A$. asclepiadis larvae were studied to determine whether there is variation among and within host-plant populations in their suitability for this specialist herbivore. There was significant variation in food preference and leaf consumption among host-plant populations, but no differences were found in larval growth and feeding on different host-plant populations. A. asclepiadis larvae preferred host-plant populations with higher alkaloid concentrations, but did not consume more leaf material from plants originating from such populations in a no-choice experiment. There was also some variation in food preference of larvae among host-plant individuals belonging to the same population, suggesting that there was variability in leaf chemistry also within populations. Such variation in larval preference among host-plant genotypes and populations may create potential for coevolutionary dynamics in a spatial mosaic.
\end{abstract}

() 2005 Elsevier SAS. All rights reserved.

Keywords: Food preference; Performance; Specialist herbivore; Plant defense; Vincetoxicum hirundinaria; Abrostola asclepiadis

\section{Introduction}

The preference of insect herbivores for certain host-plant species or individuals within a species, and their performance on those host-plants, can influence the distribution and abundance of the herbivores. Herbivore preference and performance are, in turn, strongly influenced by the quality of the host-plants. Variation in plant quality among-populations and corresponding variation in herbivore performance are prerequisites for coevolutionary dynamics in plant-herbivore interactions, while among-population variation may lead to a geographic mosaic of coevolution (Thompson, 1994, 1999).

Plant quality for herbivores is determined by the nutrient and water content of plant tissue as well as by the concentrations of secondary metabolites (Slansky and Rodriquez, 1987). Both environmental and genetic factors cause variation in plant quality among and within plant populations, conse-

\footnotetext{
* Corresponding author. Tel.: +3582333 6357; fax: +35823336550.

E-mail address: roosa.leimu@utu.fi (R. Leimu).
}

quently affecting the preference and performance of herbivores (Kennedy and Barbour, 1992). However, herbivore preference and performance are not always correlated (Vickerman and de Boer, 2002). For example, herbivores may be attracted to plants that contain high concentrations of compounds involved in host recognition but which might be of inferior nutritive quality.

Plant quality may affect generalist and specialist herbivores differently. Generalist herbivores are usually negatively affected, by host-plant defenses whereas specialists may be unaffected or attracted to defense compounds, and can even prefer higher levels of certain chemicals (e.g. Bowers, 1984; Bowers and Puttick, 1988; Van Zandt and Agrawal, 2004). It has been assumed that specialist herbivores are adapted to the chemical composition of their host-plants and, may therefore, be less affected by chemical variation (Fox, 1981). However, it has also been suggested that specialist herbivores should be more adapted to the dominant defensive set of their resource population, and should thus prefer to consume plants with an average level of defenses (Rhoades, 1979). If special- 
ist herbivores are unaffected by the defensive compounds or prefer higher concentrations they are unlikely to cause selection for increased defense in their host-plants.

The swallow-wort, Vincetoxicum hirundinaria (Asclepiadaceae), is highly poisonous to mammals and many generalist insects (Solbreck and Sillén-Tullberg, 1990), and it contains several types of secondary compounds, including alkaloids (e.g. Eibler et al., 1995; Stærk et al., 2000, 2002). Antofine, a phenanthroindolizidine alkaloid, is known for its profound cytotoxic activity (Stærk et al., 2000, 2002), but its effects on insect herbivores have not been studied. In northern Europe $V$. hirundinaria is a host-plant for a specialist folivorous moth, Abrostola asclepiadis (Lepidoptera). The larvae of A. asclepiadis are completely dependent on $V$. hirundinaria as their food source (Förare, 1995), and are thus assumed to be highly adapted to their host-plant species. Here we examined whether food choice and performance of $\mathrm{A}$. asclepiadis larvae vary among host-plant populations and whether the variation in feeding behavior is related to the mean level of antofine in the host-plant populations. In addition, we tested whether some plant genotypes are preferred to others within a host-plant population.

\section{Materials and methods}

\subsection{Study species and populations}

V. hirundinaria Medik. (syn. Cynanchum vincetoxicum (L.) Pers.; Vincetoxicum officinale Moench) is an outcrossing longlived perennial herb that grows on sunny, exposed slopes and cliffs. V. hirundinaria has a continental Eurasian distribution area, but its natural range also covers the islands and coastal areas of middle Baltic. In Finland it occurs rather frequently in the southwestern archipelago including the Aland islands. Some remnant populations are located in the southwestern mainland.

In Finland, A. asclepiadis (Lepidoptera) is the only specialist herbivore feeding on the leaves of $V$. hirundinaria, although there are two specialist species feeding on the seeds of the plant [Lygaeus equestris (Heteroptera) and Euphranta connexa (Diptera)]. A. asclepiadis is considered a local species and the populations rarely reach high densities (Förare, 1995). However, in some dense host-plant populations A. asclepiadis populations can occasionally reach high densities causing severe damage to their host-plants (personal observations). In our study area, $V$. hirundinaria is rarely attacked by generalist herbivores, and damage by these herbivores is unsubstantial (personal observations).

The female moth oviposits on leaves in June and July (Förare and Engqvist, 1996; Förare and Solbreck, 1997). Eggs hatch approximately 10 days after oviposition (Förare, 1995). The five larval instars are completed in about 5-6 weeks (Förare, 1995). The larvae used in the experiments were collected as first instar larvae or as eggs from one of the eight locations used in the study (i.e. Lammasluoto) in early July.
The larvae were reared in room temperature and under natural light conditions, and were fed leaves of plants from Lammasluoto.

Eight $V$. hirundinaria populations were selected for food choice experiments with $A$. asclepiadis. Five of these populations (Lammasluoto, Seili, Ånskär, Lohm, Jäämäluoto) are situated in the southwestern archipelago of Finland, an area located within the main area of distribution of $V$. hirundinaria in Finland. The three other populations (Naantali, Heikkilä, Juhannuskukkula) came from locations in the southwestern mainland of Finland. The distances between the populations range from 1 to $35 \mathrm{~km}$. To minimize environmental variation and to prevent natural herbivory, a common garden was established in an experimental field in the Ruissalo Botanical Garden during May 2001. Rootstocks of 12 plants (i.e. genotypes) from each of the eight host-plant populations were transplanted into the common garden. All the experiments were conducted in late July when the plants had been growing in the common garden for 2 months. Since $V$. hirundinaria is a long-lived perennial it is likely that some site effects remain, and cannot be distinguished from the genetic effects.

\subsection{Food choice among plant genotypes}

A multiple-choice feeding experiment was conducted to test if there are differences within a host-plant population in feeding preference of $A$. asclepiadis. The fourth instar larvae were simultaneously offered leaves representing eight genotypes from either Lammasluoto or Juhannuskukkula population. The leaves were of similar size and were placed on Petri dishes with a moistened filter paper on the bottom to prevent drying. One larva was put in each Petri dish. The two hostplant populations were selected because the population of Juhannuskukkula has not supported a population of A. asclepiadis for at least 10 years while the plant population of Lammasluoto supports a fairly stable population (personal observations). We conducted 10 replicates for both populations. The percentage of area consumed from each leaf was estimated after $24 \mathrm{~h}$ Among-genotype differences in the proportion of leaf area eaten were tested by using repeatedmeasures ANOVA (PROC MIXED, SAS statistical package) with the genotype as a within-effects factor. Separate analyses were conducted for the two host-plant populations. Akaike's Information Criterion was used to choose the valid covariance structure from a set of reasonable structures for repeated-measures analysis (Littell et al., 1996) (unstructured for Juhannuskukkula and compound symmetry for Lammasluoto). The values were log-transformed to meet the assumption of normal distribution.

\subsection{Food choice among-populations}

A multiple-choice feeding preference test in which third instar A. asclepiadis larvae were allowed to choose among $V$. hirundinaria leaves that originated from the eight study popu- 
lations was conducted. In each of the 24 test replicates, one larva was put on a Petri dish and offered one similar-sized fresh leaf from each of the plant populations (eight leaves per dish). Leaves were collected from eight genotypes within each population, and randomly assigned to different combinations in each replicate. The feeding preference of the larvae was monitored and the percentage of area consumed from each leaf was estimated after $40 \mathrm{~h}$ Among-population differences in the proportion of leaf area eaten were tested by using repeated-measures ANOVA (PROC MIXED, SAS statistical package) with population as the within-effects factor and compound symmetry as the covariance structure. The values were log-transformed to meet the assumption of normal distribution.

\subsection{Variation in larval growth among host-plant populations}

Effects of host-plant population on the growth of the $A$. asclepiadis larvae were examined by conducting a $24 \mathrm{~h}$ no-choice feeding experiment in solitary $50 \mathrm{ml}$ containers in the laboratory. The larvae were randomly assigned to feed on leaves of plants from each of the eight host-plant populations. Nine replicates (one or two larvae for five plant genotypes) for each population were used. During the test the larvae were third or fourth instar. The larvae and the leaves were weighed before and after the experiment. Relative growth rate (RGR) of the larvae was calculated as $\left(W_{\mathrm{e}}-W_{\mathrm{b}}\right) / W_{\mathrm{b}}$ where $W_{\mathrm{e}}$ is final biomass and $W_{\mathrm{b}}$ is initial biomass, and relative consumption rate (RCR) was calculated as leaf consumption in fresh mass divided by initial larval mass. Among-population differences in RGR and RCR were tested by conducting a two-way ANOVA with population and larval instar as independent variables.

\subsection{Chemical analysis}

Leaves for chemical analysis were collected from 8 to 10 plant genotypes per population. The leaves were freezedried and powdered. $500 \mathrm{mg}$ of leaf material was extracted with $10 \mathrm{ml}$ of a 1:1 mixture of dichloromethane and methanol. The plant material was macerated in dark for 2 days, samples were filtered and the solvent was evaporated. Quantitative analyses were performed on a Shimadzu HPLCsystem consisting of a SCL-10A VP controller, a SIL-10AD VP autosampler, a LC-10AT VP Pump, a SPD-M10A VP diodearray detektor, and a CTO-10AC VP column oven, using a $250 \times 4.6 \mathrm{~mm}$ i.d. Waters column were prepacked with Symmetry $\mathrm{C}_{18}(5 \mu \mathrm{m})$. The system was controlled by Class VP 6 software, and gradients of 20-90\% acetonitrile in ammonia formate $(10 \mathrm{mM}, \mathrm{pH} 8.85)$ for $25 \mathrm{~min}$ with a flow of $1 \mathrm{ml} / \mathrm{min}$ were used for elution of all samples. A calibration curve was made by injection of $20 \mu \mathrm{l}$ of samples containing $0.01,0.02$, $0.03,0.04$, and $0.05 \mathrm{mg} / \mathrm{ml}$ of antofine. Antofine used for the calibration curve was isolated from Vincetoxicum pumilum (Stærk et al., in preparation) and its identity as well as purity

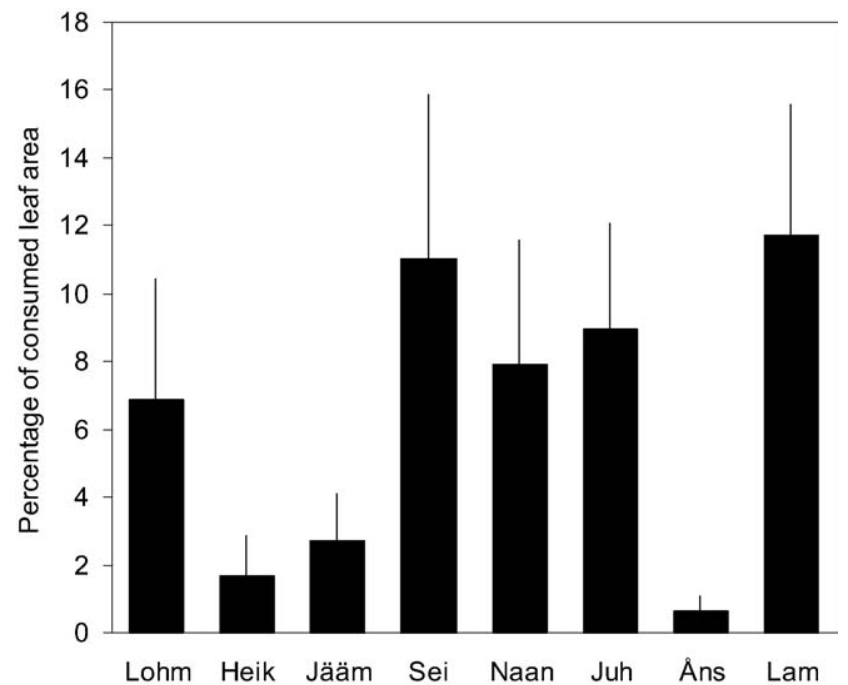

Fig. 1. Among-population variation in the percentage of consumed leaf area by $A$. asclepiadis in the food choice experiment. Population on the $x$-axis (Lohm, Jäämäluoto, Heikkilä, Seili, Naantali, Juhannuskukkula, Ånskär, Lammasluoto). Back-transformed mean \pm standard errors (S.E.s) are presented in the figure.

(> 99\%) was determined by nuclear magnetic resonance spectroscopy. The extract from the eight different populations of $V$. hirundinaria was dissolved in acetonitril, and $20 \mu \mathrm{l}$ of this solution was used for quantitative analyses. The amount of antofine in each sample was calculated from the integral of the antofine peak by the Class VP 6 software, and all results were within the limit of the calibration curve.

The relationship between antofine concentration and larval preference, RGR or RCR were tested, by conducting Pearson correlation analyses.

\section{Results}

\subsection{Food choice}

Significant differences in food choice by A. asclepiadis among the eight host-plant populations were found as measured by food consumption $\left(F_{7,161}=2.53, P=0.017\right)($ Fig. 1$)$, but no significant differences were found among genotypes within host populations (Juhannuskukkula: $F_{7,9}=2.23$, $P=0.131$; Lammasluoto: $\left.F_{7,63}=1.66, P=0.135\right)$. However, although there were obvious differences in the proportion of leaf area consumed (Fig. 2), interpretation of these results must be conservative due to small sample size and the large number of choices (Raffa et al., 2002).

\subsection{Larval growth and leaf consumption}

No significant differences were found in the RGR among the host-plant populations $\left(F_{7,58}=1.18, P=0.328\right.$; Fig. $\left.3 \mathrm{a}\right)$, but RGR varied statistically significantly between the instars $\left(F_{1,58}=49.9, P=0.0001\right)$. In contrast, significant differences were observed in relative larval consumption rates 

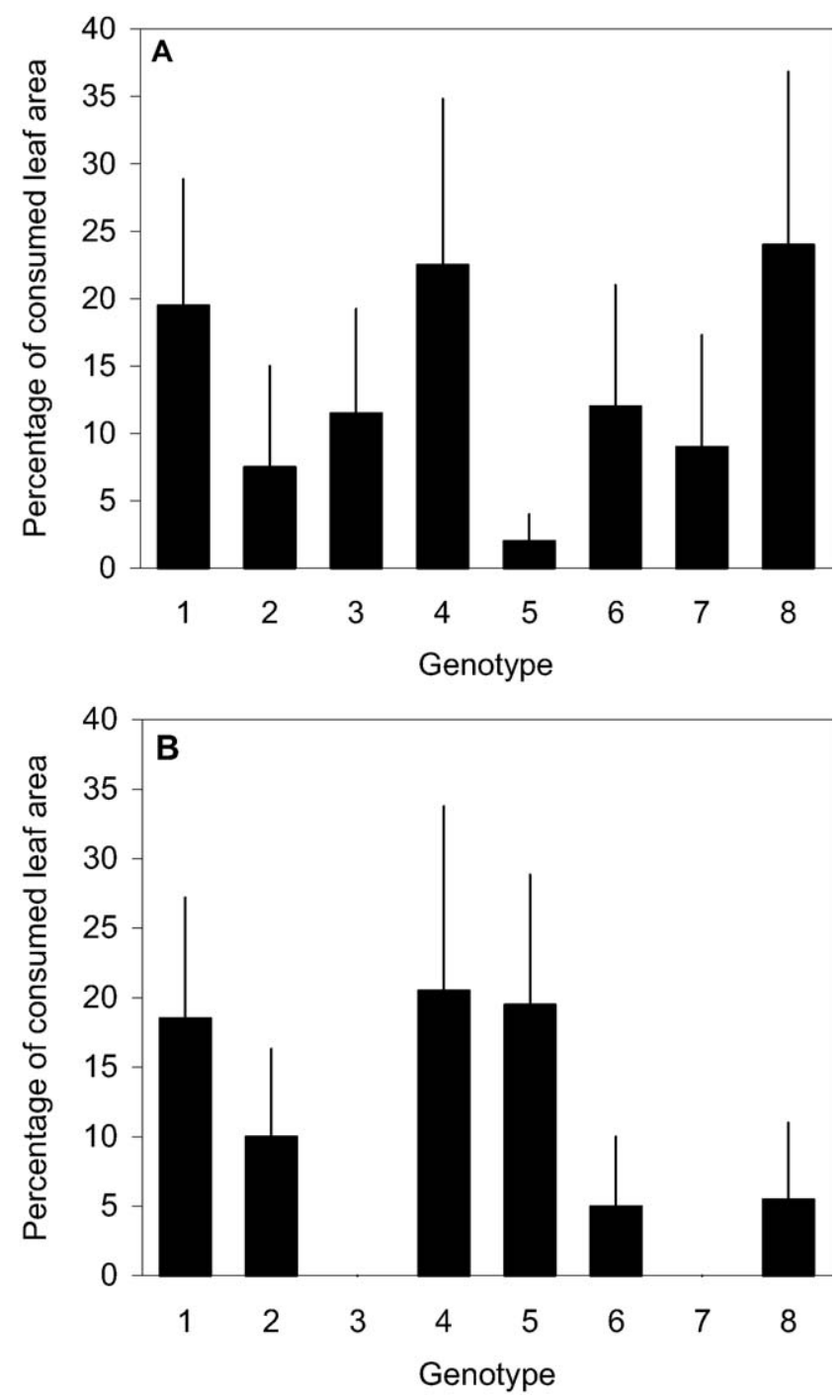

Fig. 2. Among-genotype differences in the percentage of consumed leaf area of A. asclepiadis in the food choice experiment. Genotypes from the Juhannuskukkula (a) and Lammasluoto (b) populations. Back-transformed mean \pm S.E. are presented in the figure.

among host-plant populations (RCR) $\left(F_{7}, \quad 58=2.25\right.$, $P=0.0447$; Fig. 3b) and between instars $\left(F_{1,58}=91.34\right.$, $P=0.001)$.

\subsection{Relationship between feeding behavior and antofine concentrations}

Concentrations of antofine varied among host-plant populations, and the larvae were found to prefer those with higher levels $(R=0.819, P=0.013$; Fig. $4 \mathrm{a})$. No significant relationship was found between antofine concentration and RGR ( $R=0.106, P=0.803$; Fig. 4 b) or relative consumption of the leaves $(\mathrm{RCR})(R=-0.352, P=0.392$; Fig. $4 \mathrm{c})$.

\section{Discussion}

The suitability of $V$. hirundinaria as a host-plant was found to vary among-populations and also to some extent within
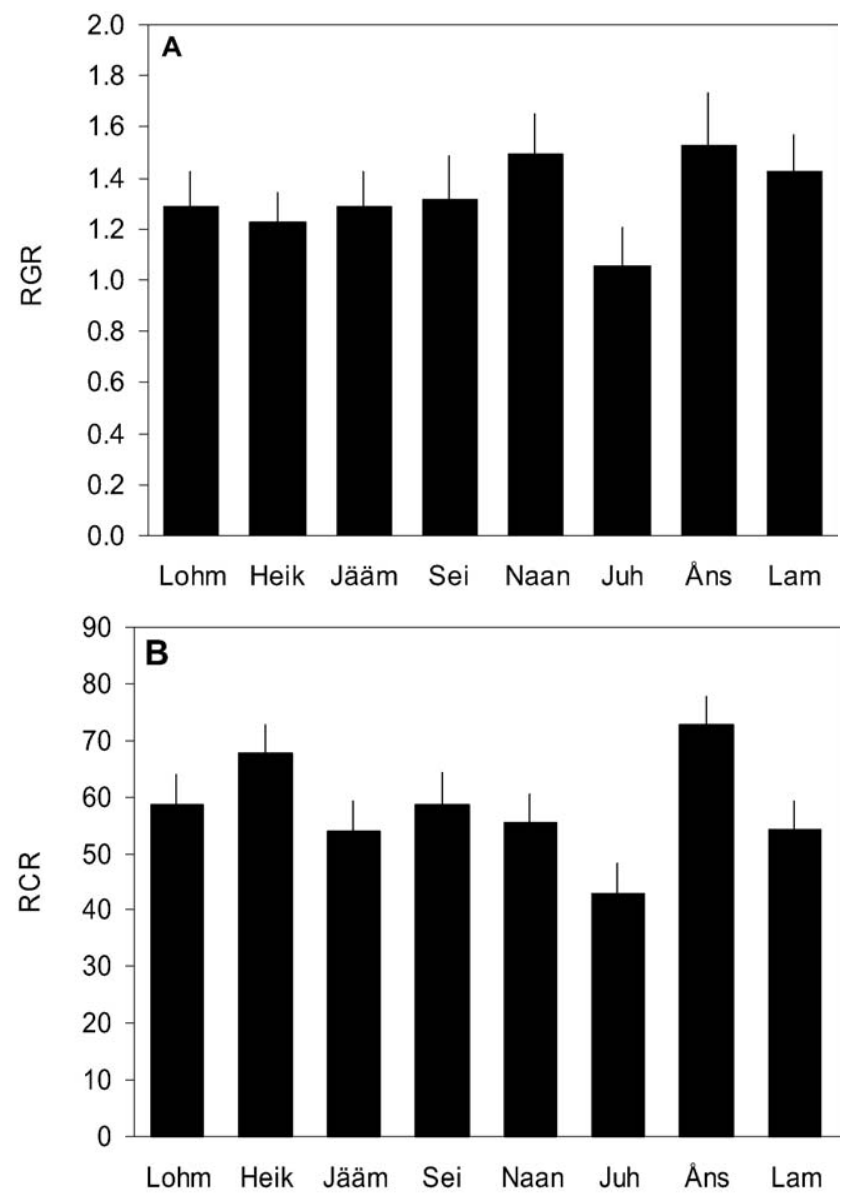

Fig. 3. Among-population variation in a) RGR and b) relative consumption (RCR; consumed leaf area in $\mathrm{mg}$ ) in the growth experiment (mean \pm S.E.). Populations on the $x$-axis (Lohm, Jäämäluoto, Heikkilä, Seili, Naantali, Juhannuskukkula, Ånskär, Lammasluoto).

populations. Host-plant populations with higher levels of antofine were preferred compared to plant populations with lower average antofine concentrations. The alkaloid levels of the host-plant populations did not influence larval growth and leaf consumption. These results suggest that antofine may be involved in host recognition by A. abrostola larvae, but consumption and growth may be determined by other factors, e.g. nutritive, compounds in the leaves.

It has previously been suggested that larval development in A. asclepiadis is not affected by variation in host-plant quality (Förare, 1995; Förare and Engqvist, 1996). Likewise, larval growth in the current study was not related to antofine concentration, but variation was found in feeding behavior, i.e. differences in food preference and consumption rates. In our study, among-population variation in feeding preferences in A. asclepiadis larvae was found as were variation in consumption rates. This was likely due to the larger spatial distribution of the host-plant populations considered in this study. Gene flow is suggested to be substantial in Asclepiadaceae (Wyatt and Broyles, 1994) and thus a larger spatial scale might be necessary to detect among-population variation in host-plant suitability related to herbivore preference. 

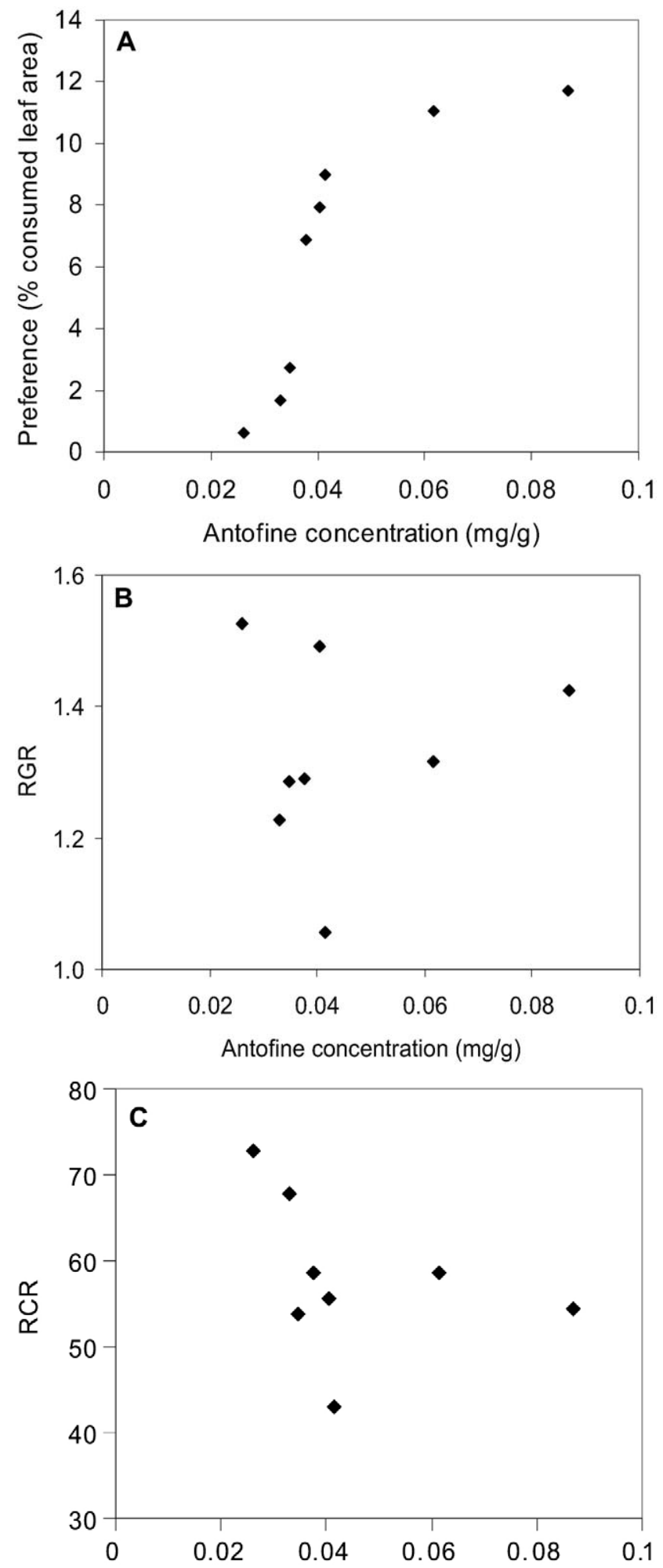

Fig. 4. Relationship between antofine concentration and a) larval preference (in choice arena), b) RGR and c) relative consumption.

It has been stated that plant defenses are more effective against generalist than specialist herbivores (Rausher et al., 1993; Agrawal, 1999). This has been suggested to be due to a long coevolutionary history between specialist herbivores and their host-plants (Ehrlich and Raven, 1964; Rausher, 1996).
Because of the reciprocal evolution, specialist herbivores are able to tolerate or detoxify the defensive compounds of their host-plants (Rhoades, 1979; Berenbaum and Zangerl, 1998). If, as observed, the larvae of A. asclepiadis prefer high content of antofine and are unaffected by its concentrations, it is unlikely that these herbivores cause strong selection for higher levels of antofine in $V$. hirundinaria. In fact, lower antofine levels may even be beneficial to plants if specialists are attracted to plants with highest contents (Malcolm, 1992; Martel and Malcolm, 2004). Accordingly, preference of larvae of a specialist herbivore for a high concentrations of a potential defensive compound, such as antofine in our study, may select for low plant defense in environments were generalist herbivores are rare.

Variation in plant quality measured, e.g. by differences in the levels of nutritive or defensive compounds observed among plants that have grown in a common environment (common garden) may be taken as evidence for genetic differences in plant quality (Fritz and Simms, 1992). Alternatively, the observed differences may partially reflect the historical and edaphic influences of the environment the plants experienced (Schwaegerle et al., 2000). In our experiments, rootstocks of long-lived plants were used to establish our hostplant stocks, and it is possible that the plants in the populations that suffered higher levels of herbivore attack were induced to increase their level of defense in the years before transplanting. This could have led to increased variation in alkaloid concentrations among plants and populations. On the other hand, the level of constitutive defense in frequently attacked populations could be high due to continuous selection by herbivores.

However, in our study the level of antofine in the leaves of $V$. hirundinaria was not significantly related to the level of herbivory by $A$. asclepiadis (calculated as a mean of 3 year's observations) in the eight populations $(R=-0.03, P=0.952$, $N=8)$. This suggests that factors other than previous herbivory by A. asclepiadis affected antofine concentrations. The relatively weak responses of the larvae to potential variation between plant genotypes and the non-significant results in the growth experiment could have been influenced by the relatively small sample sizes and thus the results must be interpreted with some caution. Furthermore, our results were obtained in a laboratory, and it is thus questionable whether most larvae are able to choose among host-plant genotypes in nature. Nevertheless, it seems likely that the more mobile larger instars of A. asclepiadis can be able to select their food plants while the smaller instars may be restricted to the plant on which the female chose to oviposit.

To conclude, spatial variation in the concentrations of antofine in $V$. hirundinaria was found among geographically distinct populations. Larval performance of the specialist herbivore A. asclepiadis was measured by preference and consumption. Larval performance as measured by consumption was not directly influenced by the observed antofine concentrations in the host-plant, but food choice was positively related to the concentrations of antofine. This suggests that 
the selection pressures from specialist herbivores on the defensive chemistry of $V$. hirundinaria may be opposite to those from generalist herbivores. Thus, depending on the types of herbivores present in the environment, this may lead to the maintenance of genetic variation in the concentrations of defense compounds within a host-plant population and to spatial differences in the mean levels of resistance among geographically distinct populations.

\section{Acknowledgements}

We thank M. Nordström, L. Nordström, K. Syrjänen, O. Vesakoski, J. Pettay, A. Muola, P. Wäli, I. Lepo, N. Heikkilä, R. Koivikko and H. Nykänen for helping to conduct the experiments. We are grateful to P. Mutikainen, A.P. Gutierrez and two anonymous reviewers for valuable comments. This study was financially supported by Jenny and Antti Wihuri Foundation, Finnish Cultural Foundation, and Finnish Entomological Society.

\section{References}

Agrawal, A.A., 1999. Induced responses to herbivory in wild radish: effects on several herbivores and plant fitness. Ecology 80, 1713-1723.

Berenbaum, M.R., Zangerl, A.R., 1998. Chemical phenotype matching between a plant and its insect herbivore. Proc. Nat. Acad Sci. USA 95, 13743-13748.

Bowers, M.D., 1984. Iridoid glycosides and host-plant specificity in larvae of the buckeye butterfly, Junonia coenia (Nymphalidae). J. Chem. Ecol. 10, 1567-1577.

Bowers, M.D., Puttick, G.M., 1988. Response of generalist and specialist insects to qualitative allelochemical variation. J. Chem. Ecol. 14, 319334.

Eibler, E., Tanner, U., Mayer, K.K., Wiegrebe, W., Reger, H., 1995. HPLCanalysis of alkaloids from Cynanchum vincetoxicum. Acta Pharm. (Zagreb) 45, 487-493.

Ehrlich, P.R., Raven, P.H., 1964. Butterflies and plants: a study in coevolution. Evolution 18, 586-608.

Fox, L.R., 1981. Defense and dynamics in plant-herbivore systems. Am. Zool. 21, 853-864.

Fritz, R.S., Simms, E.L., 1992. Ecological genetics of plant-phytophage interactions. In: Fritz, R.S., Simms, E.L. (Eds.), Plant Resistance to Herbivores and Pathogens: Ecology, Evolution, and Genetics. The University of Chicago Press, Chichago, pp. 1-12.

Förare, J., 1995. The biology of the noctuid moth Abrostola asclepiadis Schiff. (Lepidoptera, Noctuidae) in Sweden. Ent. Tidskr. 116, 179-186.

Förare, J., Engqvist, L., 1996. Suboptimal patch and plant choice by an ovipositing monophagous moth-an insurance against bad weather? Oikos 77, 301-308.
Förare, J., Solbreck, C., 1997. Population structure of a monophagous moth in a patchy landscape. Ecol. Entomol. 22, 256-263.

Kennedy, G.G., Barbour, J.D., 1992. Resistance variation in natural and managed systems. In: Fritz, R.S., Simms, E.L. (Eds.), Plant Resistance to Herbivores and Pathogens: Ecology, Evolution, and Genetics. The University of Chicago Press, Chichago, pp. 13-44.

Littell, R.C., Milliken, G.A., Stroup, W.W., Wolfinger, R.D., 1996. SAS System for Mixed Models. SAS Institute Inc., Cary, NC.

Malcolm, S.B., 1992. Prey defence and predator foraging. In: Crawley, M.J. (Ed.), Natural Enemies: the Population Biology of Predators, Parasites and Diseases. Blackwell Scientific, Oxford, UK, pp. 458-475.

Martel, J.W., Malcolm, S.B., 2004. Density-dependent reduction and induction of milkweed cardenolides by a sucking insect herbivore. J. Chem. Ecol. 30, 545-561.

Raffa, K.F., Havill, N.P., Nordheim, E.V., 2002. How many choices can your test animal compare effectively? Evaluating a critical assumption of behavioral preference tests. Oecologia 133, 422-429.

Rausher, M.D., 1996. Genetic analysis of coevolution between plants and their natural enemies. Trends Genet. 12, 212-217.

Rausher, M.D., Iwao, K., Simms, E.L., Ohsaki, N., Hall, D., 1993. Induced resistance in Ipomoea purpurea. Ecology 74, 20-29.

Rhoades, D.F., 1979. Evolution of plant chemical defense against herbivores. In: Rosenthal, G.A., Janzen, D.H. (Eds.), Herbivores: Their Interaction with Secondary Plant Metabolites. Academic Press, New York, USA.

Schwaegerle, K.E., McIntyre, H., Swingley, C., 2000. Quantitative genetics and the persistence of environmental effects in clonally propagated organisms. Evolution 54, 452-461.

Slansky Jr., F., Rodriquez, J.G., 1987. Nutritional Ecology of Insects, Mites, Spiders, and Related Invertebrates. Wiley-Interscience, New York, USA.

Solbreck, C., Sillén-Tullberg, B., 1990. Population dynamics of a seed feeding bug, Lygaeus equestris. 1. Habitat patch structure and spatial dynamics. Oikos 58, 199-209.

Stærk, D., Christensen, J., Lemmich, E., Duus, J.Ø., Olsen, C.E., Jaroszewski, J.W., 2000. Cytotoxic activity of some phenanthroindolizidine N-oxide alkaloids from Cynanchum vincetoxicum. J. Nat. Prod. 63, 1584-1586.

Stærk, D., Lykkeberg, A.K., Christensen, J., Budnik, B.A., Abe, F., Jaroszewski, J.W., 2002. In vitro cytotoxic activity of phenanthroindolizidine alkaloids from Cynanchum vincetoxicum and Tylophora tanakae against drug-sensitive and multidrug-resistant cancer cells. J. Nat. Prod. 65, 1299-1302.

Thompson, J.N., 1994. The Coevolutionary Process. The University of Chicago Press, Chicago, USA.

Thompson, J.N., 1999. Specific hypotheses on the geographic mosaic of coevolution. Am. Nat. 153 (Suppl.), S1-S14.

Van Zandt, P.A., Agrawal, A.A., 2004. Specificity of induced plant responses to specialist herbivores of the common milkweed Asclepias syriaca. Oikos 104, 401-409.

Vickerman, D.B., de Boer, G., 2002. Maintenance of narrow diet breadth in the monarch butterfly caterpillar: response to various plant species and chemicals. Entomol. Exp. Appl. 104, 255-269.

Wyatt, R., Broyles, S.B., 1994. Ecology and evolution of reproduction in milkweeds. Annu. Rev. Ecol. Syst. 25, 423-441. 